\title{
Oral ingestion of infectious antigens through beverage cans surface contamination
}

\section{Introduction}

The United States incurs approximately 76million food borne diseases per year, with 325,000 hospitalization sand 5,000deaths. From these annual rates, 14 million are identified pathogens, while 62 million pathogens remain unidentified. ${ }^{1}$ This has resulted in an information gap in the largest cause of food borne related illnesses in the US and their actual sources. One area with limited research has been the study of oral ingestion of surface contaminants from food and beverage containers. So why is a food borne illness a concern with the food and beverage industry after so many years? Recently, in an article by David Nyachyb a titled "Food borne Illness: Is It on the Rise?" raised some very importance questions about our growing inter dependence on canned and processed foods and beverages. The projected trends in globalization over the next coming years suggest that large scale food production and distribution will be greatly impacted. Since 1990 to 2009 foreign imports for produce have increased three fold in the U.S. according to the 2012 report on "The U.S. Trade Situation for Fruit and Vegetable Products". ${ }^{2}$ the beverage and food canning industry globally is expected to increase and meet this demand, potentially adding to an already existing 76 million cases of food borne illnesses annually. The increased demand could result in improper processing, handling and storage conditions that may or may not be within the control of the producer or transporter (Figure $1)$.

New technology and materials have provided the modern day advances in the canning industry, resulting in light weight recyclable containers. However, beyond these material advancements, the aluminum beverage container has not developed from its initial design over fifty years ago. ${ }^{3}$ Today's canning processes has been revolutionized with newer hygienic equipment and quality control systems in processing plants. ${ }^{4}$ Although, once beverage containers leave the manufacturer or distributor's control, contamination can easily occur from various biological or environmental sources from improper storage or use. Biological contaminants, up to and including infectious agents that can range from E. Coli (Escherichia coli), Salmonella and Hanta virus associated from in sector rodent droppings to environmental air borne contaminants, such as lead and Arsenic have been found on various food and beverage products. ${ }^{5,6}$

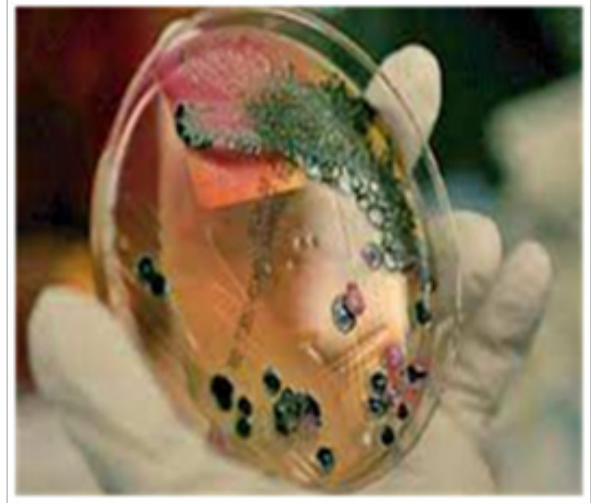

Figure I Surface contaminants on food.
Volume 7 Issue I - 2018

\author{
Martin Fekete \\ National PEO, USA
}

Correspondence: Martin Fekete,Vice President, Risk Management, National PEO, Arizona, USA, Email msfekete@msn.com

Received: May 19, 2015 | Published: January 4, 2018

\section{Study purpose}

The intent of this research study was to evaluate the influence of surface contaminate, either biological or chemical, on beverage containers, primarily aluminum cans during the consumption phase. Also, if there was any influence or causal relationship with food borne illnesses as a result of this consumption. This research article will focus only on the top portion of the beverage can. This top portion has a canal or indentation which in many instances has been the focal point where dirt and debris may collect and settle. Most consumers have at one time or another usually either wiped this area or wash edit off due to notice able dirt or debris. What researchers have not fully demonstrated is the casual relationship of this debris and the type and amount of contamination present on the top surface of these cans (Figure 2).

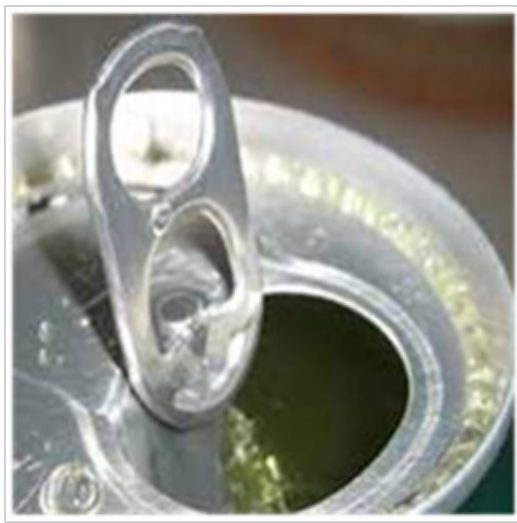

Figure 2 Contamination present on the top surface of cans.

\section{Method}

This study used a qualitative research design using secondary data analysis. A total of 50existing research articles were identified through has arch of the literature, from a larger sample of 105references. The literature search was conducted in several related are as pertaining to food borne related illnesses, food borne sources and known contaminants, along with all research pertaining to food borne illnesses for surface contamination. These arch criteria keyed in on topics of food borne contaminants, surface contamination, canning sanitation and history, food borne out breaks related to food processing and 
canning and beverage can related illnesses and studies. The sample of articles identified, although not complete, is representative of the body of work. The study included every pertinent reference readily available; however, if any relevant study was missed, it was due to over sight and not intent.

\section{Findings}

The current research findings indicated that these beverage containers have the potential to be exposed to a variety of infectious and environmental agents ranging from E. Coli (Escherichia coli), Salmonella and Hantavirus to environmental air borne contaminants, such as lead and Arsenic. ${ }^{6}$ Based on research literature reviewed, three common findings were derived from the reference sources. First was that food borne infectious pathogens are ever present in our environment and studies indicated they were commonly found in and around food storage, preparation and eating areas, regardless of the level of hygienic level. Although, there are correlations with level of hygiene and number of pathogens found. Cleaning has a positive impact on food borne illness reduction by reducing various environmental conditions in which pathogens need to survive. Many of these pathogens are typically transmitted by way of vectors, in most instance insects (cockroaches, ants, rat's mice). They serve as the reservoir host which harbors the various organisms that inflict illnesses.

Studies conducted in Texas indicated that cockroaches were an important vector in pathogen spread due to their unsanitary lifestyle. The study showed that cockroaches harbored several Enterobacteriaceae species including Salmonellas pp.., Klebsiella pp., and Escherichia's pp., along with additional species identified in the study. ${ }^{7}$ Numerous disease causing pathogens that are commonly associated with cockroaches and resulting as Entero-intestinal related illnesses were identified by the study. These pathogens, for example E.coli and Campylobacter's pp., usually transmitted by the cockroach can be typically overlooked during diagnosis of food borne illnesses that include symptoms such as abdominal cramping, diarrhea, nausea and fever.?

The second finding in the literature indicated sources of contamination on various surfaces in the workplace that may also contribute to not only inhalation hazards, but those risks associated with the ingestion of lead. This new finding suggests that the potential sources of contamination go far beyond the traditional realm of biological organisms. Industrial environments where amounts of air borne dusts and particles from grinding or processing of lead, chromium or other heavy metals may accumulate on surfaces, open cans and other items stored in or near the work environment. If these surfaces are not cleaned, the risk of ingestion of these fine particles may occur and can result in various illnesses, both of an acute and chronic nature (Figure 3).

These Contaminated surfaces are also a potential source for organisms to flourish and reside. Due to such surface contamination table surfaces, food and beverage containers, bacteria and other contaminants are likely to come indirect contact with the mouth during food and beverage consumption. ${ }^{8}$ Even though beverage manufacturers have provided state of the art facilities to ensure products safety once the product leaves their control, shipping and storage conditions can significant impact surface contamination and ultimately consumer health. ${ }^{9}$ In similar research findings, Arsenic poisoning was also identified as a potential contaminant. A recent article, demonstrated how air borne particles from industrial processes can cause surface contamination and result in a number of various illnesses, including arsenic poisoning. ${ }^{10}$ Arsenical pesticides are still used and arsenics used to treat and preserve wood. ${ }^{11}$

The likelihood of surface contamination from pesticide spraying either directly or indirectly is very possible. This possibility increases when consumer products are stored on the floor and other areas where over spray may occur. The importance of adequate storage conditions becomes critical in ensuring consumption safety. Avoiding storage in work areas and locations where pesticides spraying may expose unprotected product from these elements (Figure 4).

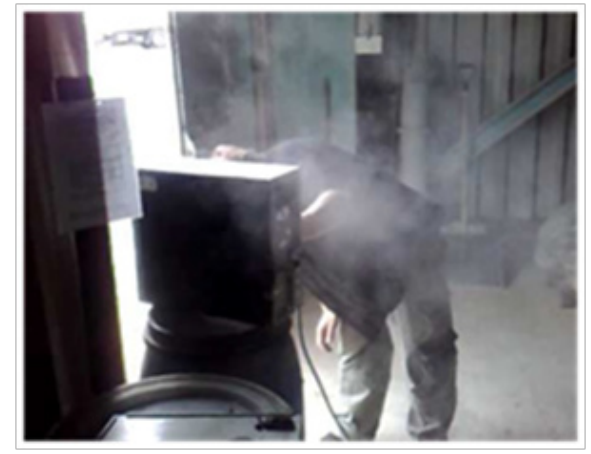

Figure 3 Industrial environment.

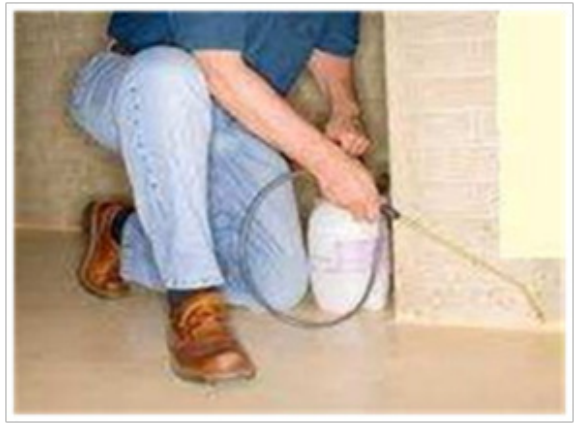

Figure 4 Surface contamination by pesticide spraying.

Finally, one of the most compelling study findings in the research literature was the relationship of contaminants conducted by Georgia Pacific Corporation in conjunction with Silliker Research. The study focused on can opener sand food and beverages can top surfaces. These items were tested for microbiological contamination and the results indicated high levels of bacterial and fungal contamination. The most common bacteria identified were Klebsiella pneumonia and Staphylococcus and spore forming Bacillus species. ${ }^{12}$ In this study, unlike similar commercial food surveys, no Escherichia coli or Salmonella species were identified on cans, however, Bacillus cereus (22 of 25cans) and Clostridium perfringens (15 of 25cans) were found in low numbers. ${ }^{12}$ This does not rule out Escherichia coli or Salmonella, but indicates that for this study these bacteria were not present as possible contaminants. The existence of Escherichia coli or Salmonella bacteria on openers and various food and beverage containers is still likely and based primarily on environmental conditions, such as pest control, hygienic practices and food storage etiquette.

\section{Conclusion}

The findings suggest that diagnosis methods for food borne illnesses are not identifying pathogens and their sources in the 62 million 
pathogens that go unidentified each year. ${ }^{1}$ This raises the question on what additional sources of contamination may be contributing to these high illness rates. Studies have shown that infectious agents ranging from E. Coli (Escherichia coli), Salmonella and Hanta virus, Klebsiella pneumonia and Staphylococcus and spore forming Bacillus species to environmental airborne contaminants, such as lead and Arsenic exist in the general environment and available in and around food preparation, handling storage and eating locations. Specific studies have provided actual data that food and beverage can surfaces do contain known pathogens associated with food borne illness. ${ }^{1-12}$

Additional, studies indicated that environmental conditions also play an important role in both food borne and other acute and chronic illnesses, associated with Lead and Arsenic poisoning. ${ }^{8}$ Washing the surface of the cans did provide some reductions $\mathrm{P}=0.061$ of surface bacteria, with water and wiping being the most effective method $\mathrm{p}<0.0003 .{ }^{12}$ Food cans according to the study were more easily cleaned than beverage cans because of the tab area, which indicates beverage cans more than likely have a greater propensity to hold bacteria under the tab and varying uneven surfaces. The results and outcome may be an increase in the likely hood of food borne illness due to surface contamination by pathogens during consumption even after washing or rinsing.

The study has presented evidence that it is very likely that amounts of various bacteria and other surface contaminants are consumed each time when a beverage is consumed from a can, even with rinsing and wiping. Findings suggest that storage and handling of these containers play an important part in this process. Concerns over plastic containers, specifically Bisphenol A (BPA) as a health risk continue to grow, making the can industry the primary alternative for food and beverage containers. ${ }^{13}$ The challenge moving forward is to maintain the clean lines of the containers once they leave the manufacturing facility through improved container designs that prevent contamination and better storage practices. The relationship of these surface contaminants to the actual causal relationship of food borne illness needs further research and study to determine the exact causal relationship and it impact on the 62 million unidentified food borne illnesses a year.

\section{Acknowledgement}

None.

\section{Conflict of interest}

None.

\section{Funding}

None.

\section{References}

1. Gamarra RM, Katz J. Food Poisoning. USA, Medscape. 2012.

2. Johnson R. The US Trade Situation for Fruit and Vegetable Products. USA, Congressional Review Service. 2012;D7-7500:RL34468.

3. Busch J. An Introduction to the Tin Can. Historical Archeology 1981;15(1):95-104.

4. Corbitt AJ, Bennion N, Forsythe SJ. Adenylate Kinase Amplification of ATP Bioluminescence for Hygiene Monitoring in the Food and Beverage Industry. Lett Appl Microbiol. 2000;30(6):443-447.

5. Hunter PR. Bacteriological, Hygienic and Public Health Aspects of Food and Drink from Vending Machines. Crit Rev Environ Control. 2009;22(34):151-167.

6. Altekruse SF, Cohen ML, Swerdlow DL. Emerging Foodborne Diseases. Emerg Infect Dis. 1997;3(3):285-293.

7. Pechal JL, Austin J, Gold R, et al. Epidemiology and Spatial Relationship of Bacteria Associated with Periplaneta Americana (Blattodea: Blattidae) in Central Texas. J Agric Urban Entomol. 2007;24(4):205-216.

8. Lammering AM, Fazil A. Hazard Identification and Exposure Assessment for Microbial Food Safety Risk Assessment. Int J Food Microbiol. 2000;58(3):147-157.

9. Cheftel CJ. Netherlands: Advances in Food Protection: Emerging Risks Related to Food Technology. Springer. 2011.

10. Rowden AK, Ramachandran TS. USA: Pathophysiology and Etiology of Lead Toxicity. Medscape. 2011.

11. Dyro FM, Ramachandran TS. USA : Neurological Manifestations of Arsenic Intoxication. Emedicine: Medscape. 2012.

12. Gangar MB, Schultz A, Curiale MS, et al. A Microbial Survey of Food Service Can Openers, Food and Beverage Can Tops and Cleaning Methodology Effectiveness. Food Service Technology. 2003;3(3-4):123132.

13. Zeratsky K. What is BPA and What are the Concerns About BPA. USA Mayo Clinic. 2012. 